\title{
СОЦИАЛЬНОЕ ВКЛЮЧЕНИЕ ПОЖИЛЫХ: ПРОДЛЕНИЕ ЗАНЯТОСТИ ИЛИ «ПРОДВИНУТЫЙ» ДОСУГ?
}

Основной исследовательский вопрос статьи заключался в том, связана ли мотивация пожилых для обучения на предлагаемых государством курсах ИКТ-грамотности только с их желанием разнообразить досуг, освоить новую практику, не актуализируя при этом рациональные смыслы получаемых навыков. Исследование проводилось в рамках стратегии множественного кейс-стади. В статье раскрывается мотивация посещения специализированных курсов компьютерной грамотности, анализируется взаимодействие пожилых как непосредственно в процессе обучения на курсах, так и при самостоятельном овладении компьютером. В центре исследования - случай одной из организаций («Школы третьего возраста» Невского района Санкт-Петербурга), на базе которой возник целый ряд сообществ пожилых, а также широко представлены обучающие возможности, в том числе, курсы компьютерной грамотности. На втором этапе исследования, в качестве дополнительного вопроса выяснялось, что, если приобретение навыка ИКТ-грамотности не является центральным фактором включения пожилых в новую деятельность, то может ли разнообразие предлагаемых услуг создавать условия для улучшения включения пожилых в активную жизнь через сферу досуга и создания новых сообществ? Выявлено, что предоставление возможностей для участия пожилых в разных формах деятельности, направленных на создание долгосрочных партнерских, социально ориентированных, а не клиентских отношений, могло бы принести значимые результаты, в развитии взаимопомощи пожилых или их помощи в других организациях. Однако исследованный случай организации, существовавшей 12 лет в Невском районе и оставшейся без государственной поддержки, показывает, что государство не заинтересовано в партнерских отношениях с пожилыми. А государственные структуры скорее игнорируют общественные организации для пожилых, предлагающие «продвинутый»,

Александра Владимировна Дмитриева - к.с.н., научный сотрудник Университета ИТМО, Санкт-Петербург, Россия. Электронная почта: alexandra.dmitrieva.uni@gmail.com 
а не развлекательный досуг и возможности создания новых сообществ в период ухода из трудового коллектива.

Ключевые слова: пожилые, обучение ИКТ, Школа третьего возраста, продвинутый досуг, социальные услуги

DOI: $10.17323 / 727-0634-2018-16-1-37-50$

Цель статьи - проанализировать возможности участия пожилых в разных формах деятельности, направленных на создание долгосрочных партнерских, социально ориентированных отношений вместо клиентских. Начиная работу над исследовательским проектом в 2014 г., мы предполагали, что основным фокусом станет анализ того, как улучшение доступности курсов компьютерной грамотности на базе центров социального обслуживания (КЦСОН) и городских библиотек может способствовать социальной инклюзии пожилых. В первую очередь, это новые формы занятости пожилых, обновление их профессиональных навыков, интеграция в современный рынок труда, предполагая заинтересованность общества и государства, как это уже происходит в других странах (Taylor, Earl 2016).

Доказательных исследований для оценки влияния обучения информационно-коммуникационным технологиям (ИКТ) на увеличение занятости или повышение качества жизни пожилых или социальную инклюзию в России практически не предпринималось. Социальное включение через обучение ИКТ можно считать не аналитической, а скорее нормативной моделью взаимодействия пожилых и современного общества. Серия наших исследований за период 2014-2016 гг. (автоматизированный контент-анализ социальных сетей по ключевым словам, вторичный анализ данных больших социологических «фабрик» ФОМ, ВЦИОМ, Левада-Центр, опрос пожилых в СанктПетербурге, проведенный в 2015 г., многочисленные интервью и фокус-группы) не подтверждают наличие обусловленности новой занятости пожилых появившимися навыками владения ИКТ (Grigoryeva, Dmitrieva 2016; Григорьева, Келасьев 2016). В то же время пожилые проявляют настойчивость и заинтересованность в том, чтобы овладеть определенными навыками использования ИКТ, в первую очередь, расширяющими их возможности коммуникации и потребления (Григорьева, Чернышова 2009).

Акцентируя внимание на освоении ИКТ как на инструменте включения пожилых, мы исходили из теоретических предпосылок (Вершинская 2017, 2011; Сапонов, Смолькин 2012; Григорьева, Чернышова 2009), объясняющих возникновение большого числа новых исключенных стремительным формированием общества потребления и процессов глобализации. Параллельно резвившийся концепт «информационного общества» обозначил появление нового типа «информационно-коммуникационно-сетевого» исключения, связанного с недоступностью для части общества технологических новинок, с одной стороны, и отсутствием постоянно обновляемых 
знаний для их использования, с другой (Григорьева и др. 2014; Taylor, Earl 2016). В это же время на повестке дня - глобальное старение населения, особенно в развитых европейских странах (European Commission 2013, 2014), что актуализировало вопрос о социальном исключении, связанном с ограничением знаний и ресурсов для полноценного включения пожилых в современный мир информационных технологий. Уже в 2000 г. международная «Окинавская хартия» рекомендовала:

уделять особое внимание нуждам и возможностям людей, пользующихся меньшей социальной защищенностью, людей с ограниченной трудоспособностью, а также пожилых граждан, и активно осуществлять меры, направленные на предоставление им более легкого доступа в мир ИКТ (Окинавская хартия 2000).

На уровне повседневной жизни сигналом о появлении существенной группы исключенных из информационного общества пожилых стала стремительная потеря связи между молодыми и пожилыми родственниками (Григорьева, Чернышова 2009; Вершинская 2011). Ранний уход на пенсию, потеря интереса к трудовой деятельности и/или нежелание продления занятости также могут способствовать исключению. Таким образом, возникает не группа исключенных из занятости по причине информационного и технологического отставания, а группа отказавшихся от продолжения трудовой деятельности в пенсионном возрасте в пользу получения в основном бесплатных социальных услуг - образовательных или чисто развлекательных. В этом случае речь идет о досуге пожилых, а не новых рабочих квалификациях, получаемых на курсах по овладению ИКТ. Отметим, что в 2016 г. ситуация в Санкт-Петербурге меняется, многие досуговые услуги становятся платными или частично платными, а в регионах менее обеспеченных, процесс, возможно, шел быстрее, так как оплата услуг легитимирована законом, вступившим в силу с 01.01.2015 г. (Федеральный закон 2013).

Очень мало исследований посвящено изучению изменения досуга пожилых в изменяющихся современных обществах. Именно досуг, а не оплачиваемая работа, все чаще осмысляется новым поколением пожилых как способ самореализации и самопрезентации индивида (Хиггс и др. 2014). Некоторые исследователи отмечают роль «презентизма» в современном обществе, в котором прошлое и будущее почти полностью сведены к роли инструментов для достижения целей настоящего, в данном случае, демонстрации себя (Артог 2004; Курилла 2017). При этом пожилые успешно конкурируют с молодежью, пользуясь новыми информационными технологиями (Mellor et al. 2008). Российские исследователи обращают недостаточно внимания на пожилых как новых потребителей в этом контексте. «Смену оптики» предлагают английские социологи, которые показывают, что поведенческие и потребительские практики седеющих 
«бэби-бумеров» заметно отличаются от практик пожилых предшествующих поколений (Biggs et al. 2007). Пол Хиггс с коллегами показывают, что эти практики носят «эгоистический» характер, передаваемый следующим поколениям (Хиггс и др. 2014). Поэтому в современных условиях необходимо перейти от экстенсивного расширения доступа к обучению ИКТ и электронным взаимодействиям к изучению результатов такого обучения, достигнутых за последние годы.

Таким образом, вместо изучения включения пожилых в изменяющуюся сферу труда через обучение новым технологиям, мы исследовали, связана ли их мотивация для обучения на предлагаемых курсах только с досугом - желанием разнообразить его, освоить новую практику. В этом случае внимание переключается на досуговые практики пожилых в новом информационном и технологическом социальном контексте. Тем не менее на втором этапе исследования в качестве дополнительного вопроса сформулирована гипотеза, возвращающая исследовательский интерес к проблеме инклюзии: если приобретение навыков в области ИКТ не является центральным фактором включения пожилых в новую рабочую деятельность, то может ли разнообразие предлагаемых услуг создавать условия для улучшения включения пожилых в общество через сферу досуга и создания новых сообществ?

\section{Методы сбора данных}

Закончив работу над сбором данных на первых двух этапах качественного исследования (интервью с преподавателями курсов компьютерной грамотности и с пожилыми, обчающимися на курсах), мы пришли к выводу о необходимости «перенастраивания» нашей исследовательской оптики. Это связано с тем, что мотивы продолжения занятости или повышения уровня навыков фактически не прозвучал и в тех интервью, которые были собраны в 2014-2015 гг. Во что же в повседневной жизни трансформируется ожидание заботы о пожилых? Совпадают ли ожидания пожилых и направленность государственных социальных служб, предоставляющих пожилым возможности для новых форм досуга?

Качественная часть нашего проекта проводилась в рамках стратегии множественного кейс-стади. Выявили мотивацию пожилых для посещения специализированных курсов компьютерной грамотности, проанализировали взаимодействие пожилых как непосредственно в контексте обучения на курсах, так и при самостоятельном овладении компьютером, что в итоге формирует их повседневные пользовательские практики или объясняет причины отказа от пользования компьютером. Затем исследован кейс организации, на базе которой возник целый ряд сообществ пожилых, а также представлены обучающие возможности, в том числе, предоставлялись курсы компьютерной грамотности. 
Эта организация - «Школа третьего возраста» на базе КЦСОН Невского района, нетипичная для городской палитры центров социального обслуживания. В отличие от других центров, содержание деятельности Школы минимально определялось «спущенными сверху» стандартами обслуживания, а основной была задача лидера организации, стремящейся из «клиента социальной службы» сделать активиста гражданского общества, а из социально-досугового отделения - «народную школу». Кроме того, Школа предоставляла действительно широкий спектр услуг для пожилых. А истории взаимодействия пожилых и Школы могут быть примером того, как пожилые, включаясь в разные сферы деятельности, впоследствии могут самостоятельно организовать свой досуг, взаимопомощь и вести активный образ жизни.

В течение полугода были собраны полуструктурированные интервью (11) с курсистами Школы и проведены фокус-группы (3) с ее администрацией, с курсистами, ставшими сотрудниками Школы, с рядовыми курсистами. Материалы интервью обработаны в программе Atlas.ti, предназначенной для качественного анализа данных.

\section{Результаты и обсуждение}

Школа третьего возраста начала свою работу в 2004 г. в рамках программы «Старшее поколение», в составе Центра социального обслуживания населения (социальной службы) Невского района Санкт-Петербурга. Первоначально автор и бессменный директор Школы не предполагала, что будет заниматься развитием организации, работа которой направлена именно на пожилых (Инт. 1). Источником вдохновения для нее была идея датской «народной школы», задача которой не обучать в буквальном смысле, а воодушевить пришедших на самоорганизацию, на сплочение и объединение ради достижения какой-то общей цели. Однако обстоятельства сложились таким образом, что построить «народную школу» стало возможным только при условии переформатирования деятельности под потребности пожилых людей. Так появилась Школа третьего возраста, идея которой заключалась в том, чтобы создать платформу для включения старшего поколения в формирование гражданского общества на местном уровне.

\section{Пожилые: активисты самоорганизации или клиенты социальных служб?}

Главным отличием Школы от традиционной социальной службы является отход от каких-либо субординационных требований, от создания клиентских отношений с пожилым в пользу равных или близких к этому. Эта идея воспроизводится через деятельность всех сотрудников Школы, а не только руководителя, поэтому кадровый вопрос наиболее важен (Инт. 2, Инт. 3). По замечанию директора, наличие активной гражданской 
позиции у сотрудников - основной критерий «оседания» в Школе, а отсутствие ее - причина частых кадровых изменений. За 12 лет существования Школы, которая осенью 2016 г. в очередной раз подходила к переломному этапу (решался вопрос о поиске нового помещения), понимания общих целей с районной и городской администрацией так и не было достигнуто ${ }^{1}$.

Предлагать развлекательные мероприятия в Школе считается неэтичным, так как руководством подразумевается, что, выйдя на пенсию, человек хоть и оказывается дезориентирован, но не должен обязательно смещать свои интересы в сторону исключительно ведения домашнего хозяйства (Инт. 1, 2, 3). Именно в этот период может появиться готовность заняться обобщением своего опыта, которым он готов поделиться с другими, если помочь развиваться в таком направлении. Задача в этом случае - подготовить к принятию ответственности за себя и свою деятельность, чтобы решение было принято самостоятельно и не казалось обременительным. Школа устроена для людей, которые еще не уверены в том, что готовы, но им важно встречаться со своими ровесниками, чтобы начать сначала: с самоидентификации, с понимания близкого круга. Именно с общения и формирования некоего нового сообщества начинается переход на более высокий уровень, на котором рефлексируется профессиональный путь, полупрофессиональные навыки, любимые занятия.

Согласно нашим интервью с администрацией школы и дискуссиям на фокус-группах, одной из основных сложностей при работе с пожилыми становится отсутствие у них навыков самоуправления, так как люди часто не планируют старость, она «вдруг» наступает. Сотрудникам Школы приходится заново обучать пожилых распоряжаться свободным временем конструктивно, вплоть до обучения коммуникативным навыкам вне привычного рабочего или семейного круга общения. При ежегодном анкетировании по оценке удовлетворенности прохождением Школы, очень многие пожилые пишут, что приходят туда «за общением». Школа не создает специального пространства для общения, оно возникает органически, но уже по воле и при активном участии со стороны самих пожилых.

Закончив семестр, многие снова возвращаются в Школу, потому что альтернативы нет или другие варианты досугового обслуживания не подходят (Инт. 4-5). После прохождения нескольких семестров, пожилым гораздо легче осмелиться на реализацию собственных инициатив и проектов. Подход многократного повторения курсов обучения в Школе поощряется и руководителем. Но прежде всего она является ресурсным центром для создания

\footnotetext{
1 За время, прошедшее после нашего исследования в 2016 г., Невский КЦСОН отказался от альянса со Школой, которая была вынуждена переехать в новое, очень небольшое, по сравнению с досуговым отделением, помещение и находится в процессе трансформации, переходя к платным образовательным услугам.
} 
подобных мини-школ при библиотеках самими бывшими учениками. Отмечая, что Школа - плод тяжелой и долгой работы, ее руководитель понимает, как непросто отважиться на организацию подобного проекта в меньшем масштабе. В любом случае, даже достигнув высокого уровня необходимых компетенций, пожилые, как правило, наталкиваются на глубинную проблему - конкурирующее общество, функционирующее на основе прописанных и обязательных для исполнения инструкций. В такой среде реализация инициативных проектов оказывается затруднительной.

Среди курсов Школы, которые самим пожилым удалось развить в самостоятельные проекты, сотрудники выделяют несколько. Так, выпускники курса моды организовали клуб, «гастролирующий» по демонстрационным площадкам, они меняют социальный стереотип о женщинах старшего возраста, показывая их элегантность и выдержанный стиль. С 2007 г. в Школе действует отдельное издательское направление: многие ценят возможность печатать собственные произведения, позволяющие осмыслить какой-то период своей жизни, а книги часто дарят близким.

Таким образом, один из важнейших проектов Школы - выводить взаимодействия пожилых за свои стены, включая мероприятий в своем районе, встречи друг с другом за ее пределами, что поощряет социальную жизнь территориального сообщества. При этом Школа становится «ключевым словом», паролем, соединяющим жителей района: при упоминании о ней, люди общаются ближе. Порой это работает для тех, кто еще не проходил обучение в школе, но знает о ее существовании, поскольку идеи Школы распространяются в информационном пространстве.

\section{От «народной школы»}

\section{к самостоятельным инициативам и сообществам}

Для многих первичным мотивом для посещения Школы, как и в других случаях, была возможность пройти курсы компьютерной грамотности. Затем они включались в семестровую работу, состоящую из разных направлений, внутри которых образовывались «ядра» наиболее активных пожилых, стремящихся применять, развивать и передавать другим свой профессиональный опыт вкупе с «апгрейдом», сделанным в Школе.

В отличие от других социально-досуговых организаций, Школа не только давала возможность комплексного обучения, но и была готова предоставлять собственные ресурсы. С одной стороны, это материальные возможности (помещения, оборудование), с другой - идеи для реализации, как на базе Школы, так и за ее пределами, которые сотрудники готовы предлагать и развивать совместно с пожилыми. Именно такие идеи создают мотивацию для продолжения обучения и появления собственных инициатив.

Например, одной из успешных выпускниц курсов журналистики, руководитель предложила заняться развитием информационного направления - распространением сведений о Школе среди жителей Невского 
района, укреплением ее авторитета, репутации, популярности. Так, с написания статьи рекламного характера в газете «Полезно пенсионерам» началась работа по созданию отдела, где занимаются не только распространением информации о Школе, но и своеобразным «внутренним аудитом». В ходе такого аудита проводятся микроисследования и публикуются «автоэтнографические» тексты пожилых о пожилых, поднимающие проблемы активизации и адаптации пожилых, а также рассказывающие о позитивных изменениях в социальной политике.

Другой вариант прихода к созданию собственного сообщества или объединения (направления/клуба/отдела) - мотив непрерывного обучения и последовательное восполнение недостающих навыков для воплощения «старой мечты». Один из курсистов рассказал о том, как прошел длинный путь через кино-курсы «Сам себе режиссер», затем занимался журналистикой, закончил компьютерные курсы и после этого вместе с другими курсистами организовал Литературное объединение «Невские берега», которое развивается и публикует произведения своих членов (Инт. 6, Инт. 8).

Поддержка самых старших курсистов через создание благоприятной атмосферы, теплое общение и совместное времяпрепровождение в Школе - также важный мотив продолжения занятий и способ проявления чувства солидарности внутри сформировавшегося сообщества:

Вот одна из женщин, ей 87 лет, она кандидат наук, озеровед, она уже мало что руками может сделать, красиво чтобы, но ей обстановка нравится, она приезжает, чтобы с нами побыть. Она посидела и говорит: мне с вами очень хорошо, в атмосфере вашей (фокус-группа).

Для многих пожилых Школа становится «толчком» для рефлексии прожитого «жизненного материала», переосмысления воспоминаний, профессионального опыта. Так возникают литературные сборники «Вестник», создаются пособия по кинопроизвоству, проводятся публичные выступления пожилых, конкурс «Музыкальная свеча» и даже курсы разговорного французского.

Как и сотрудников, в момент проведения исследования пожилых курсистов волновал вопрос о будущем Школы, связанный с необходимостью покинуть помещение, которое она занимала. Лишившись возможности посещать Школу, пожилые рискуют остаться не только без альтернатив, связанных с обучением и проведением свободного времени, но, в первую очередь, без любимого круга общения и взаимной поддержки:

И школа достигает того, что она продекларировала. Мы хотим дать открытый урок, куда приходим, и говорим: «Мы - клуб». А школа нас поддерживает, школа - как стеночка такая, мы опираемся. А теперь каждый сам будет вариться, не в общем котле теперь [имеется в виду необходимость смены помещения]. И это безумно жалко. Мы же не только своим кружочком общались, мы и с фотографами, и с художниками, а теперь одни будем. По коридорам вместе ходили, чай пили. Это все давало такое чувство. Монолитное, а теперь такого не будет... (фокус-группа). 
Хотя в каждом районе Петербурга существуют КЦСОН, включающие досуговые отделения, проектов, подобных рассмотренному кейсу, на базе государственных социальных служб не создавалось. В настоящий момент, когда городская администрация предъявляет жесткие требования к количественным показателям эффективности, Школе становится все сложнее обосновывать сложившийся подход к работе с пожилыми. Она едва ли может конкурировать со вторым досуговым подразделением социальной службы в Невском районе. К тому же, примерно треть повторно участвует в обучении в последующих семестрах. Гонка за показателями происходит на межрайонном уровне, где все участники полагают, что чем больше клиентов, тем успешней деятельность и тем более защищенная позиция у конкретного социального центра.

Получается, что государство видит в потреблении пожилыми возможно большего числа досуговых услуг потенциал для их социальной активизации. В данном случае власть действует рационально, встраивая представителей любого возраста или поколения в универсальную рыночную стратегию, в которой, чтобы быть как все, необходимо потреблять, а чтобы потреблять то же, что и все, нужно иметь соответствующие навыки (Ильин 2007). Конструируя новую группу потребителей, как бы совершенствуя пожилых, государство не направляет усилия на возможности использования полученных навыков в других областях жизни, сводя их до потребительской сферы. Многие пожилые с радостью принимают такую идеологию, соглашаясь с тем, что именно «этого достойны», тем более с поддержкой государства. Уникальные же проекты, ориентированные не только на досуг, но и на социальное включение и самоорганизацию пожилых, подобно рассмотренному, оцениваются руководством КЦСОН и Комитетом по социальной политике Санкт-Петербурга как недостаточно эффективные.

\section{Выводы}

Большинство преподавателей в КЦСОН или библиотеках, с которыми мы проводили интервью не имеют четкого и тем более формализованного представления об измерении эффективности услуг, которые они предоставляют. «Обратная связь» с бывшими учениками реализуется через сбор восторженных, но неконкретных откликов о прохождении курсов, оставляемых в группах ВКонтакте, созданных в процессе обучения. В расчет идут количественные показатели - число КЦСОН, задействованных в программе компьютеризации пожилых, число пожилых, посещающих курсы. Качественная оценка услуги не формулируется даже как цель, важным является сам факт того, что государство обеспечивает возможность взаимодействия пожилых с современными технологиями, предполагая, что это влечет за собой их социальное включение. 
Услуга обучения ИКТ, равно как и другие «досуговые» услуги, не была изначально разработана с учетом критериев оценки эффективности. Обучение не ориентировано на создание устойчивых сообществ пожилых с использованием интернета, а стихийные интернет-сообщества слабо структурированы. Во многом ситуация является типичной в том смысле, что само по себе предоставление услуги зачастую становится синонимом эффективности. Это замещает возможные измерения того, насколько необходимой или важной для социального включения является реализация услуги для целевой группы, на которую она направлена.

Безусловно, внедрение курсов компьютерной грамотности как некое «свежее» звено в цепочке отработанных услуг, предлагаемых КЦСОН, обеспечивает определенные условия для включения пожилых в более плотное сообщество и соответствует положениям недавно принятой «Стратегии действий в отношении пожилых» (Правительство РФ 2016). Однако, как правило, это включение носит ограниченный временем прохождения курсов характер и редко выливается в какую-то активность, направленную на других.

Предоставление возможностей для участия пожилых в разных формах деятельности, направленных на создание долгосрочных партнерских, социально ориентированных, а не клиентских отношений могло бы принести более значимые результаты, как для самих пожилых, так и для общества в целом. Однако кейс-стади организации, действующей 12 лет и оставшейся без господдержки, показывает, что государство не заинтересовано в партнерских отношениях с пожилыми и их НКО, предлагающими «продвинутый», а не развлекательный, досуг и возможности создания новых сообществ.

\section{Список информантов}

Инт. 1 Ж., 43 г. Руководитель Школы третьего возраста

Инт. 2 Ж., 28 л. Проектный менеджер Школы

Инт. 3 Ж., 26 л. Помощник директора, специалист по социальной работе Школы

Инт. 4 М., 69 л. $\quad$ Сотрудник Школы, в прошлом - курсист

Инт. 5 Ж., 55 л. Сотрудница Школы, в прошлом - курсист

Инт. 6 Ж, 63 г. Курсист

Инт. 7 М., 78 л. Курсист

Инт. 8 Ж., 72 г. Курсист

Инт. 9 М., 77 л. Курсист

Инт. 10 Ж., 71 г. Курсист

Инт. 11 Ж., 72 г. Курсист 


$\begin{array}{lll}\text { Инт. } 12 & \text { Ж.,73 г. } & \text { Курсист } \\ \text { Инт. } 13 & \text { Ж., } 69 \text { л. } & \text { Курсист } \\ \text { Инт. } 14 & \text { Ж., 70 л. } & \text { Курсист }\end{array}$

\section{Выражения благодарности}

Исследование выполнено в Университете ИТМО за счет гранта Российского научного фонда (проект № 14-18-03434) по теме: «Модели взаимодействия общества и пожилых людей: исследование возможностей социальной инклюзии». Продлен на 2017-2018 гг.

\section{Список источников}

Артог Ф. (2004) Типы исторического мышления: презентизм и формы восприятия времени. Отечественные записки, (5). Доступно по ссылке: http://www.strana-oz. ru/2004/5/tipy-istoricheskogo-myshleniya-prezentizm-i-formy-vospriyatiya-vremeni (дата обращения: 11 февраля 2018).

Вершинская О.Н. (2017) Адаптация людей старшего возраста к виртуальному миру. Философские науки, (6): 148-159.

Вершинская О.Н. (2011) Цифровой раскол - новый вид экономического неравенства? Доступно по ссылке: http://viperson.ru/wind.php? ID=637647 (дата обращения: 20 февраля 2018).

Григорьева И. А., Келасьев В.Н. (2016) Интернет в жизни пожилых: намерения и реальность. Социологические исследования, (11): 82-85.

Григорьева И.А., Бершадская Л. А., Дмитриева А. В. (2014) На пути к нормативной модели отношений общества с пожилыми людьми. Журнал социологии и соичальной антропологии, (3): 151-167.

Григорьева И.А., Чернышова С.П. (2009) Новые подходы к профилактике социального исключения пожилых. Журнал сочиологии и сочиальной антропологии, (2): 186-196.

Ильин В.И. (2007) Потребление как дискурс. Журнал социологии и социальной антропологии, (1):3-26.

Курилла И.И. (2017) История в эпоху победившего презентизма: инструмент борьбы за идентичность, ресурс для политики или научное знание? Сахаровский иентр, 18 апреля 2017 г.

Окинавская хартия (2000) Окинавская хартия глобального информационного общества. Доступно по ссылке: http://federalbook.ru/files/SVAYZ/saderzhanie/Tom\%206/I/ hartia.pdf (дата обращения: 11 февраля 2018).

Правительство РФ (2016) Стратегия действий в интересах старшего поколения граждан в Российской Федерации до 2025 года N 164-р от 5.02.2016 г.

Сапонов Д. И., Смолькин А.А. (2012) Социальная эксклюзия пожилых: к разработке модели измерения. Мониторинг общественного мнения, (5): 83-92. 
Федеральный закон (2013) Об основах сочиального обслуживания граждан в РФ № 442 от 28.12 .2013 г.

Хиггс П., Джиллеард К., Джонс Я.Р. (2014) Эгоистичное поколение: исследование концепции. Власть, (3): 10-30.

Biggs S., Phillipson C., Leach R., Money A. (2007) Baby Boomers and Adult Ageing: Issues for Social and Public Policy. Quality in Ageing and Older Adults, 8 (3):32-40.

European Commission (2014) Active Ageing and Healthy Living: A Human Centered Approach in Research and Innovation as a Source of Quality of Life. Amsterdam: IOS Press.

European Commission (2013) Long-Term Care in Ageing Societies - Challenges and Policy Options. Commission Staff Working Document. Available at: http://ec.europa.eu/social/ BlobServlet?docId=12633\&langId=en (дата обращения: 11 февраля 2018).

Higgs P., Gilleard C. (2010) Generational Conflict, Consumption and the Ageing Welfare State in the UK. Ageing and Society, (8):439-451.

Grigoryeva I., Dmitrieva A. (2016) ICT Use as a New Consumer Practice of Elderly People and Their Quality of Life. SGEM 2016. Conference Proceeding. Albena. Available at: http://www.sgemsocial.org/index.php/sgem-social-topics/sgem-social-topics-psychology. DOI: 10.5593/sgemsocial2016B12 (дата обращения: 11 февраля 2018).

Mellor D., Firth L., Moore K. (2008) Can the Internet Improve the Well-being of the Elderly. Ageing International, 32 (1):25-42.

Taylor P., Earl G. (2016) The Social Construction of Retirement and Evolving Policy Discourse of Working Longer. Journal of Social Policy, 45 (2): 251-68. 
Alexandra Dmitrieva

\title{
ACHIEVING THE SOCIAL INCLUSION OF ELDERLY PEOPLE: A CONTINUATION OF EMPLOYMENT OR 'ADVANCED' LEISURE?
}

\begin{abstract}
The study was conducted within the framework of a multiple case study strategy. Firstly, we tried to uncover what motivated elderly people to attend specialized courses in ICT literacy. Secondly, we analysed processes of interaction among the elderly in the context of training courses and selfmastering computer literacy, such as emerging everyday user practices and reasons for their avoidance. We also studied one organization as a case: 'School of the Third Age' in Nevsky district, St. Petersburg. The School created a number of opportunities for the surrounding small elderly communities and provided a wide number of educational options, including computer literacy courses. The main research question was whether motivation to study at these courses is mainly connected to a desire to diversify leisure time, or, more about mastering new practices even when such skills were not implemented toward concrete rational goals? At the second stage of the study, an additional question emerged: if the acquisition of ICT literacy skills is not a central factor attracting the elderly in any new activity, can a variety of services create the conditions for improving their integration into active life through leisure and creating new communities? This paper suggests this can be understood a form of prestigious consumption. As a result of the study we made several conclusions. Providing opportunities for elderly to participate in different forms of activities aimed at creating long-term partnership, more socially-oriented than client-oriented, and probably could bring more meaningful results both for the elderly themselves and for society as a whole. However, the school we examined, which has existed since 2004 and remained without state support, claims the Government is not interested in partnership with elderly people and their NGOs, regardless of whether they offer 'advanced' leisure and opportunities for creating new communities in the period of leaving work and employment.
\end{abstract}

Keywords: elderly people, social inclusion, active and advanced leisure

DOI: 10.17323/727-0634-2018-16-1-37-50

\section{References}

Artog F. (2004) Tipy istoricheskogo myshleniya: prezentizm i formy vospriyatiya vremeni [Types of Historical Thinking: Presentism and Forms Time Perception] Otechestvennye zapiski [Domestic Notes], (5). Available at: http://www.strana-oz.ru/2004/5/tipy-istoricheskogomyshleniya-prezentizm-i-formy-vospriyatiya-vremeni (accessed 18 February 2018).

Biggs S., Phillipson C., Leach R., Money A. (2007) Baby Boomers and Adult Ageing: Issues for Social and Public Policy. Quality in Ageing and Older Adults, 8 (3):32-40.

Alexandra Dmitrieva - PhD in Sociology, research fellow at IFMO University, St. Petersburg, Russian Federation. Email: alexandra.dmitrieva.uni@gmail.com 
European Commission (2014) Active Ageing and Healthy Living: A Human Centered Approach in Research and Innovation as a Source of Quality of Life. Amsterdam: IOS Press.

European Commission (2013) Long-Term Care in Ageing Societies - Challenges and Policy Options. Commission staff working document. Available at: http://ec.europa.eu/social/BlobS ervlet?docId=12633\&langId=en (accessed 18 February 2018).

Federal Law (2013) Ob osnovakh sotsial'nogo obsluzhivaniya grazhdan v RF [On Principles of Social Insurance of Citizens of the Russian Federation] No. 442 from 28.12.2013.

Grigoryeva I., Dmitrieva A. (2016) ICT Use as a New Consumer Practice of Elderly People and their Quality of Life. SGEM 2016. Conference Proceeding. Albena. Available at: http://www.sgemsocial.org/index.php/sgem-social-topics/sgem-social-topics-psychology. DOI: 10.5593/sgemsocial2016B12 (accessed 18 February 2018).

Grigor'eva I., Kelas'ev V. (2016) Internet v zhizni pozhilykh: namereniya i real'nost' [Internet in a Life of Elderly: Intentions and Reality]. Sotsiologicheskie issledovaniya [Sociological Research], (11): 82-85.

Grigor'eva I., Bershadskaya L., Dmitrieva A. (2014) Na puti k normativnoy modeli otnosheniy obshchestva s pozhilymi lyud'mi [On a Way to Normative Model of Relationships between Society and Elderly]. Zhurnal sotsiologii $i$ sotsial'noy antropologii [The Journal of Sociology and Social Anthropology], (3): 151-167.

Grigor'eva I., Chernyshova S. (2009) Novye podkhody k profilaktike sotsial'nogo isklyucheniya pozhilykh [New Approaches to Prevent Social Exclusion among Elderly People]. Zhurnal sotsiologii sotsial 'noy antropologii [The Journal of Sociology and Social Anthropology], (2): 186-196. Higgs P., Gilleard C. (2010) Generational Conflict, Consumption and the Ageing Welfare State in the UK. Ageing and Society, (8): 439-451.

Il'in V. (2007) Potreblenie kak diskurs [Consumption as Discourse]. Zhurnal sotsiologii i sotsial'noy antropologii [The Journal of Sociology and Social Anthropology], (1):3-26.

Okinawa Charter (2000) Okinavskaya khartiya global'nogo informatsionnogo obshchestva [Okinawa Charter on Global Information Society]. Available at: http://federalbook.ru/files/SVAYZ/ saderzhanie/Tom\%206/I/hartia.pdf (accessed 18 February 2018).

Khiggs P., Dzhilleard K., Dzhons Ya. R. (2014) Egoistichnoe pokolenie: issledovanie kontseptsii [Selfish Generation: Exploring the Concept]. Vlast' [Vlast], (3): 10-30.

Kurilla I. (2017) Istoriya v epokhu pobedivshego prezentizma: instrument bor'by za identichnost', resurs dlya politiki ili nauchnoe znanie? [History in an Age of winning Presentism: An Instrument of Struggle for Identity, Resource for Policy or Scientific Knowledge?]. Sakharov Center, 18.04.2017.

Mellor D., Firth L., Moore K. (2008) Can the Internet Improve the Well-being of the Elderly. Ageing International, 32 (1):25-42.

Government Decree (2016) Strategiya deystviy v interesakh starshego pokoleniya grazhdan $v$ Rossiyskoy Federatsii do 2025 goda [Strategy of Actions for Support an Older Generation of Russian Federation Citizens by 2025] No. 164-r from 5.02.2016.

Saponov D., Smol'kin A. (2012) Sotsial'naya eksklyuziya pozhilykh: k razrabotke modeli izmereniya [Social Exclusion of Retired Persons: Towards Elaboration of the Model of Measurement]. Monitoring obshchestvennogo mneniya [The Monitoring of Public Opinion: Economic and Social Changes Journal], (5): 83-92.

Taylor P., Earl G. (2016) The Social Construction of Retirement and Evolving Policy Discourse of Working Longer. Journal of Social Policy, 45 (2): 251-268.

Vershinskaya O. (2011) Tsifrovoy raskol - novyy vid ekonomicheskogo neravenstva? [Is the Digital Gap a New Type of Economic Inequality?]. Available at: http://viperson.ru/wind.php? ID=637647 (accessed 18 February 2018).

Vershinskaya O.N. (2017) Adaptatsiya lyudey starshego vozrasta k virtual'nomu miru [Adaptation of People 60+ to Virtual World]. Filosofskie nauki [Philosophical Sciences], (6): 148-159. 